\title{
The evolution of the western rift area of the Fimbul Ice Shelf, Antarctica
}

\author{
A. Humbert ${ }^{1}$ and D. Steinhage ${ }^{2}$ \\ ${ }^{1}$ Institute of Geophysics, KlimaCampus, University of Hamburg, Bundesstraße 55, \\ 20146 Hamburg, Germany \\ ${ }^{2}$ Alfred Wegener Institute for Polar and Marine Research, Am Alten Hafen 26, \\ 27568 Bremerhaven, Germany
}

Received: 25 March 2011 - Published in The Cryosphere Discuss.: 11 April 2011

Revised: 4 October 2011 - Accepted: 6 October 2011 - Published: 24 October 2011

\begin{abstract}
This paper studies the evolution of a zone in the Fimbul Ice Shelf that is characterised by large crevasses and rifts west of Jutulstraumen, an outlet glacier flowing into Fimbulisen. High-resolution radar imagery and radio echo sounding data were used to study the surface and internal structure of this rift area and to define zones of similar characteristics. The western rift area is dominated by two factors: a small ice rumple that leads to basal crevasses and disturbs the homogeneity of the ice, and a zone with fibre-like blocks. Downstream of the rumple we found down-welling of internal layers and local thinning, which we explain as a result of basal crevasses due to the basal drag at the ice rumple. North of Ahlmannryggen the ice loses its lateral constraint and forms individual blocks, which are deformed like fibres under shear, where the ice stream merges with slower moving ice masses of the western side. There, the ice loses its integrity, which initiates the western rift system. The velocity difference between the slow moving western part and the fast moving extension of Jutulstraumen produces shear stress that causes the rifts to form tails and expand them to the major rifts of up to $30 \mathrm{~km}$ length.
\end{abstract}

\section{Introduction}

Fimbulisen is an ice shelf fringing Dronning Maud Land, East Antarctica, located from $71.5^{\circ} \mathrm{S}$ to $69.5^{\circ} \mathrm{S}$ and $3^{\circ} \mathrm{W}$ to $7.5^{\circ} \mathrm{E}$ (Fig. 1). With a size of $\sim 39400 \mathrm{~km}^{2}$ it is the largest ice shelf in the Håkon VII Sea. The ice stream Jutulstraumen,

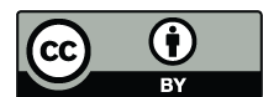

Correspondence to: A. Humbert

(angelika.humbert@zmaw.de) the largest outlet glacier in Dronning Maud Land, feeds the central part of the ice shelf. The inflow of this fast ice stream (about $700 \mathrm{ma}^{-1}$ ) divides the ice shelf into a fast and two slow moving parts and builds up an ice tongue at the calving front, the Trolltunga. The junction of fast and slow moving flow units contributes to shear stress. Along the eastern margin of the ice stream, this builds a classical shear margin with a field of densely distributed small cracks at the surface. The western part of Fimbulisen on the other hand, consists of an extensive field of large and wide crevasses and rifts, as satellite and airborne images show. Radar imagery, penetrating the ice surface up to several metres depth reveal even more structures, that are not visible in optical imagery. Figure 2a shows an overview of this crevasse and rift area, which we denote western rift area of Fimbulisen. This area covers a size of approximately $30 \mathrm{~km}$ width and $100 \mathrm{~km}$ length.

The existence of the western rift area presumably also plays a role in large calving events of Fimbulisen. In 1967 the entire ice tongue calved off and formed an about $5000 \mathrm{~km}^{2}$ large iceberg, which drifted $13 \mathrm{yr}$ through the Weddell Sea (McClain, 1978; Vinje, 1975; Swithinbank et al., 1977). Although the calving of Trolltunga was suggested to be triggered by a collision of an iceberg originating from the Amery Ice Shelf, the cause of the calving is rather the rifting perpendicular to the western margin of the ice front of the tongue. Vinje (1975) compares the shape of Trolltunga in 1959 and as iceberg in 1973, showing that two rifts existing already in the late fifties remained on the calved Trolltunga. These rifts were documented in the flights of the Norwegian Antarctic Expedition 1956-1960 and are likely to have evolved from the western rift zone this paper is subjected to.

Published by Copernicus Publications on behalf of the European Geosciences Union. 


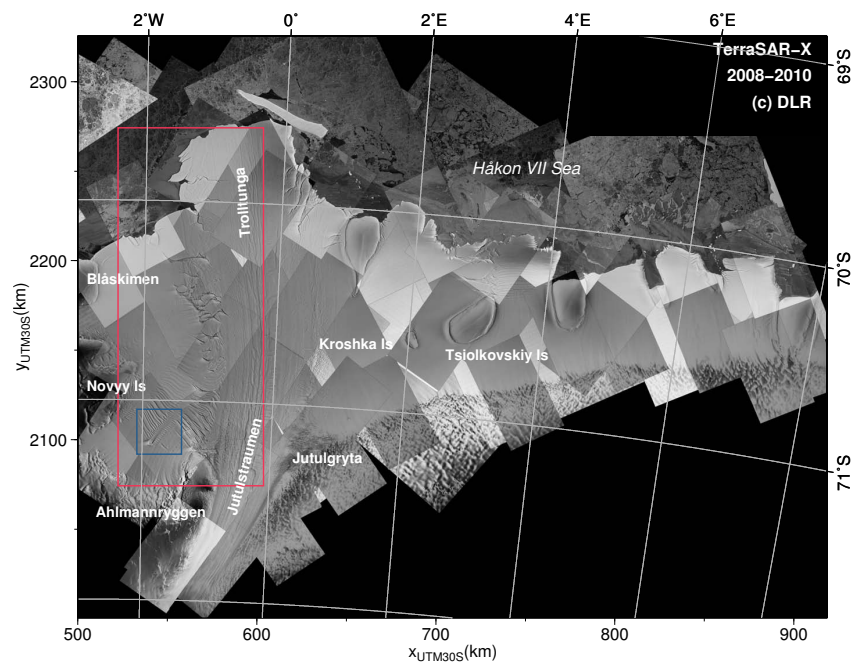

Fig. 1. Map of Fimbulisen showing TerraSAR-X mosaic derived from images in stripmap mode and ScanSAR mode acquired between 2008 and 2010.

This study aims to investigate the origin of the western rift area and to explain the structures found in radar imagery and radio echo sounding (RES). To this end, high-resolution radar imagery are used to define areas with similar surface characteristics. In order evaluate if the surface characteristics are linked to flow units in the vertical, radio echo sounding data was analysed and used to classify these units. Finally, the identified areas were incorporated in a numerical flow model to check the completeness of the classification and to investigate the softening effect of the damage. The latter part goes beyond the scope of this paper and will thus not be discussed here.

\section{Database}

The database consists of radar satellite imagery, as well as airborne radio echo sounding data, which are all described in detail below. Radar imagery is used to identify locations at which the internal structure of the ice is analysed using airborne radio echo sounding. At one location we additionally use a single optical image for comparison, however we do not discuss ASTER imagery as a separate part of the database.

\subsection{TerraSAR-X high resolution radar imagery}

We used high resolution radar imagery obtained by the XBand Synthetic Aperture Radar TerraSAR-X. TerraSAR-X stripmap mode images acquired between 2008 and 2010 were geolocated using high-precision orbit parameters, leading to sub-pixel position accuracy (Fritz and Eineder, 2009). We assembled a mosaic with a resolution of $12.5 \mathrm{~m}$ from ScanSAR and stripmap mode scenes, which is shown in Fig. 1.
The penetration of the X-band radar into snow is often considered as a disadvantage, as the definite penetration depth is unknown. In our case, the penetration of the radar signal into the firn is an advantage, as it leads to an integrated signal over a shallow layer and hence provides more information than a surface signal. The scattering of the radar wave in firn can be separated into two contributions: surface scattering and volume scattering. Diffusive and specular scattering builds the surface scattering and hence, the scattering depends on the surface roughness and moisture. In dry snow, the radar wave penetrates through the surface layer and volume scattering at inhomogeneities, as well as scattering along internal boundaries of layers of different density, becomes the dominating factor. Davis and Poznyak (1993) observed a penetration depth of a $10 \mathrm{GHz}$ signal in firn of the East Antarctic cold and dry plateau region of $4.7 \mathrm{~m}$. Rott et al. (1993) found for $10.3 \mathrm{GHz}$ a penetration depth of $8.1 \mathrm{~m}$ in a dry snow zone in western Dronning Maud Land. In April 2005 during the SVALEX campaign, DLR's airborne E-SAR system was flown above the summit region of the Austfonna ice cap, Svalbard. Acquired single pass interferometric SAR data covering on-ground deployed corner reflectors as well as on site gained snow/firn profiles were utilized to estimate the $\mathrm{X}$-Band penetration depth. The snow/firn profiles reveal very thin ice layers or very thin ice lenses indicating no perfect dry snow zone (R. Metzig (DLR), personal communication, 2011). The scattering volume depth for the $9.6 \mathrm{GHz}$ VV polarisation radar signal was estimated to be about $16.2 \mathrm{~m}$; the depth of the scattering phase center was determined to be approximately $4.5 \mathrm{~m}$ for this location (R. Scheiber (DLR), personal communication, 2011). For the TerraSAR-X $9.65 \mathrm{GHz}$ radar signal we consider a penetration depth of $8-10 \mathrm{~m}$ to be realistic for the dry snow zone.

The TerraSAR-X mosaic was used to define areas with similar surface and near-surface structure. The structural characteristics are rift patterns, flow patterns and the absence of texture. The structural mapping was performed between $2.5^{\circ} \mathrm{W}$ and $7.5^{\circ} \mathrm{E}$, however, we focus here on the area up to $1^{\circ} \mathrm{E}$. The obtained zones of similar surface characteristics allow nevertheless only a two dimensional assignment. In order to asses if the surface structure allows to map units of similar internal structure, the vertical structure was explored along already available airborne RES profiles.

\subsection{Airborne radio echo sounding}

All RES flights used in this study, were performed by the Alfred Wegener Institute between 1996 and 2008 with a radio echo sounding system developed at the TU HamburgHarburg for application in polar regions. The radar has a centre frequency of $150 \mathrm{MHz}$ and a selectable transmitted pulse length of $60 \mathrm{~ns}$ or $600 \mathrm{~ns}$, resulting in a vertical resolution of approximately 5-10 m (60 ns), respectively $50 \mathrm{~m}$ (600 ns). The short pulse allows to study the internal structure of ice sheets and shelves along the flown transects. For details on 

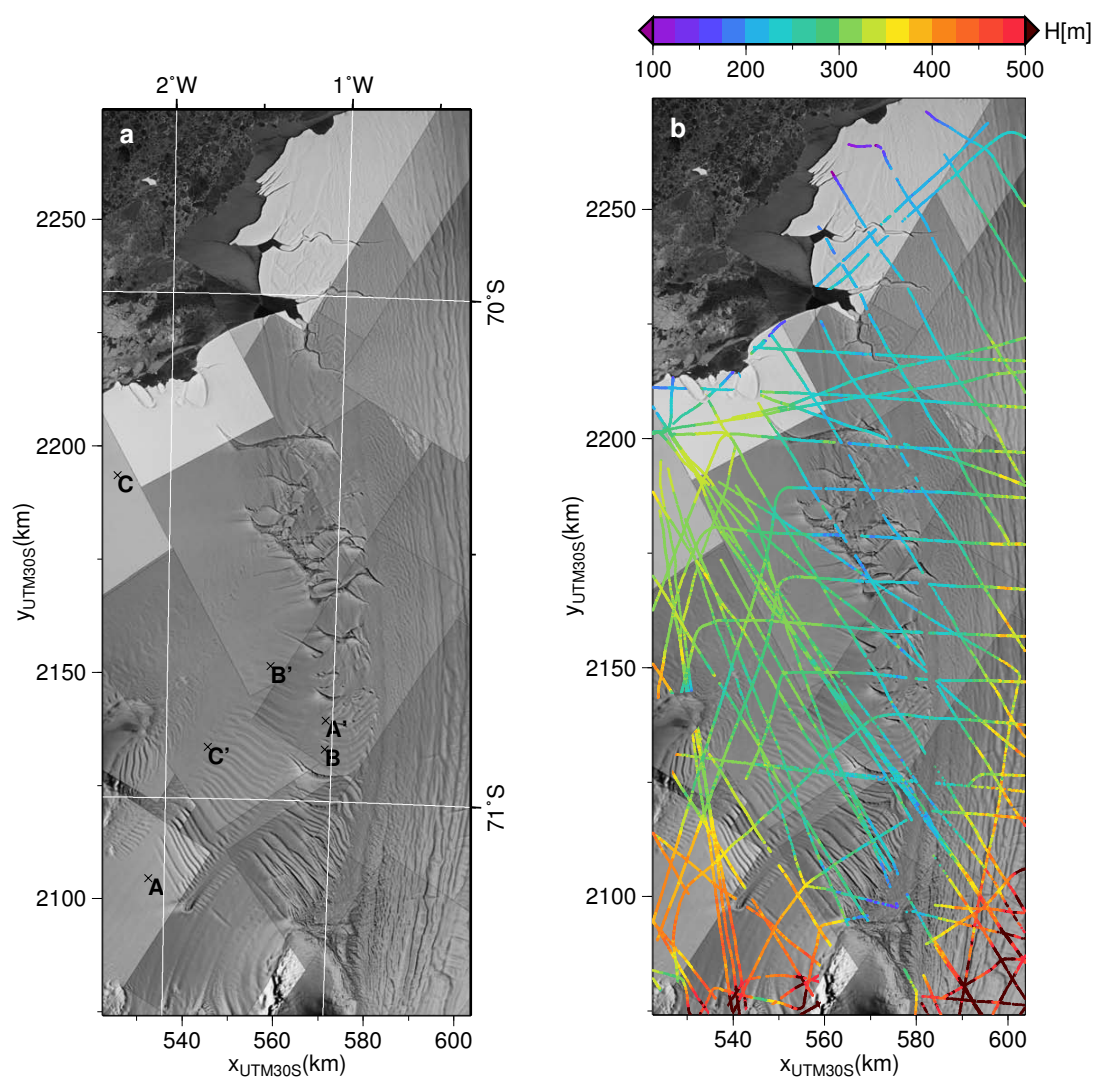

Fig. 2. Panel (a): subset of the TerraSAR-X mosaic showing the western rift area of Fimbulisen, as well as large parts of the extension of Jutulstraumen. Panel (b): same as left, with superimposed ice thickness along RES profiles in colour.

the RES system see Nixdorf et al. (1999). The horizontal resolution after a tenfold stack was typically $70 \mathrm{~m}$. Beside stacking, the data were filtered, an amplitude correction, and a static correction were applied.

As most flights above Fimbulisen were carried out for a geophysical survey mapping magnetic and gravity field. Especially the western part of the ice shelf is covered by two regular partly overlapping flight patterns with a line spacing of $10 \mathrm{~km}$. In sum 70 profiles with a total length of $11580 \mathrm{~km}$ are available over the ice shelf for extraction of the ice thickness. Twenty-two of these profiles were acquired with using the $60 \mathrm{~ns}$ pulse and 48 with $600 \mathrm{~ns}$. The resulting ice thickness dataset of Fimbulisen is based on roughly 63500 data points. Therefore the ice thickness is well known and the gradients in thickness, e.g. close to the inflow of the ice stream are well documented. The transformation from two way travel time to ice thickness was made by using a radar velocity of $0.17 \mathrm{~m} \mathrm{~ns}^{-1}$ plus $8.8 \mathrm{~m}$ in order to account for the higher velocities in firn (Blindow, 1994; van Autenboer and Decleir, 1969). The ice thickness obtained from all available RES profiles is displayed colour coded along the profiles on top of on TerraSAR-X image for the western part of the ice shelf in Fig. $2 b$ and discussed below.
For the purpose of understanding the internal structure of the ice shelf, all twenty-three $60 \mathrm{~ns}$ pulse profiles and a single one with $600 \mathrm{~ns}$ pulse length that covers the northernmost part of Trolltunga were analysed, as there is no $60 \mathrm{~ns}$ pulse profile available in that area. The location of these profiles are drawn as thin white lines in Fig. 4. About $6260 \mathrm{~km}$ of RES profiles were manually analysed for the internal structure of the ice, namely the appearance and shape of internal layers, hyperbolae, as well as bottom reflections. The layering was detected each hundredth shot and at closer spacing where necessary. The layering was determined in the vertical marking beginning and end of the layering. Hyperbolae were detected in two different ways: hyperbolae at the base, which are often rather densely distributed, where assigned as horizontal sections in the radargram, whereas hyperbolae above the base were marked as individual location, with a vertical coordinate representing the location of the crest. The beginning and end of areas where the bottom reflections were lost entirely, respectively discontinuous, were marked as well. Occasionally sparsely spaced hyperbolae still indicate some kind of bottom reflections. Special attention was given to the classification of the shape of the internal layering where it is not horizontally oriented. We have two classes which represent two clear patterns, down-welling and rippled 


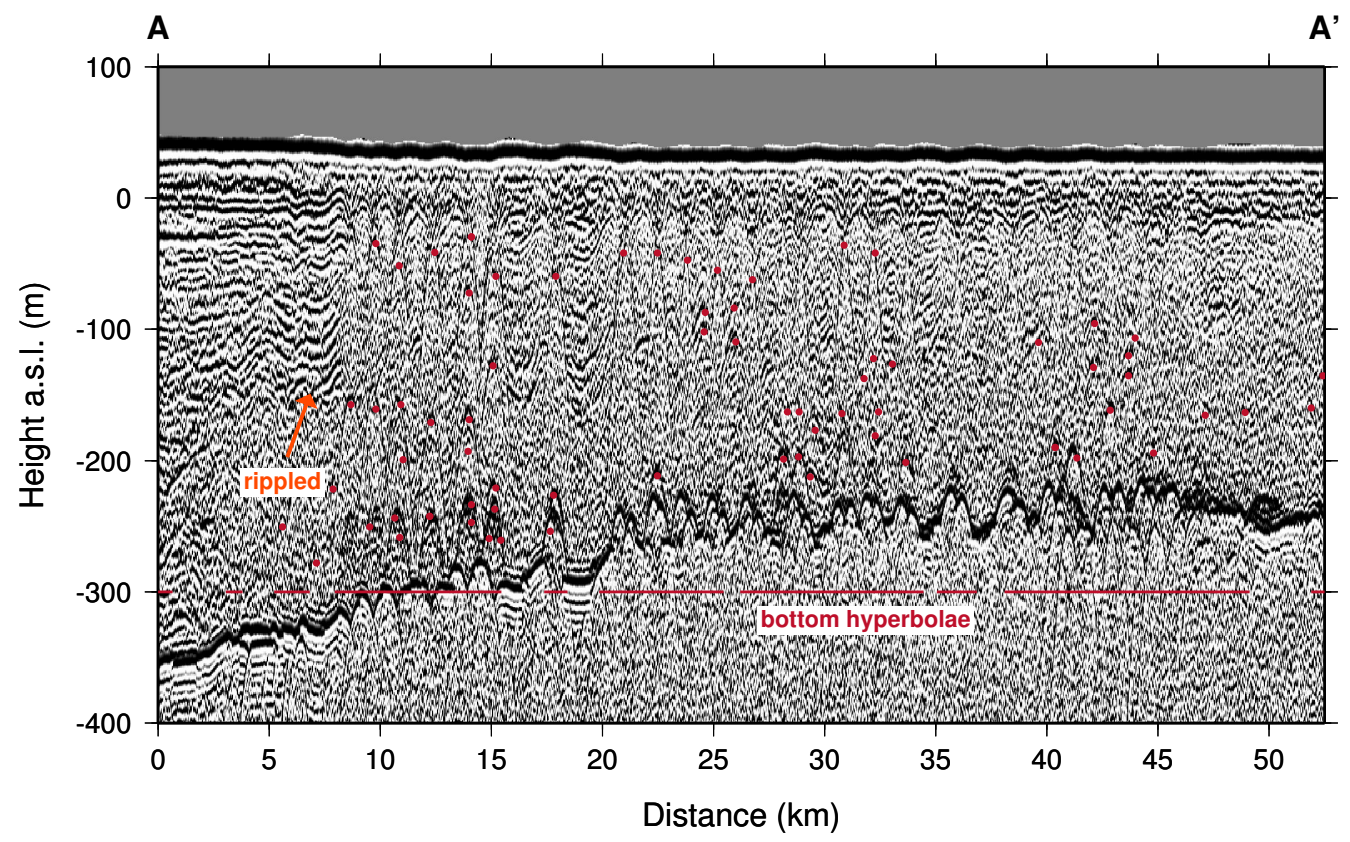

Fig. 3a. Radargram showing a $60 \mathrm{~ns}$ profile acquired in 2004 reaching from A to A' (locations of are shown in Fig. 2a). The red dots mark the apex of internal hyperbolae and the red line at $-300 \mathrm{~m}$ denotes the occurrence of bottom hyperbolas. An example for rippled layering in pointed out by the light red arrow at $\mathrm{km} 7$.

and one class that marks features that exhibit predominantly a kink in the radar layers (kink-like). A further class (unclear) that marks everything else that is not in agreement with typical vertical structure and thus sums up different shapes, which could not be split in different classes. For these four classes we detected the horizontal and vertical extent of the respective regions in the radargram. Examples of the characteristics mapped in the radargrams are given in the three profiles in Figs. 3a-c, for location see Fig. 2a. Internal hyperbolae are marked by red dots and red lines below the ice shelf base indicates sections with bottom hyperbolae. Figure $3 \mathrm{a}$ exhibits at $\mathrm{km} 7$ a good example of a $5 \mathrm{~km}$ long section of rippled layering indicated by a light red arrow. An example for kink-like isochrones, marked by the purple arrow at $\mathrm{km} 11.5$, for approximately $1 \mathrm{~km}$ and down-welling layering indicated by the turquoise arrow at $\mathrm{km} 6$ is given in Fig. 3b. The manual classification has been performed repeatedly and independent, so reproducibility is assured.

\section{Synthesis of the data}

The two radar systems are observing clearly two different parts of the ice shelf: the airborne $150 \mathrm{MHz}$ RES is insensitive in the upper $50 \mathrm{~m}$, whereas the $9.65 \mathrm{GHz}$ TerraSAR$\mathrm{X}$ signal penetrates presumably only $8-10 \mathrm{~m}$, but definitely less than the theoretical $30 \mathrm{~m}$ (Ulaby et al., 1982). Thus we cannot quantitatively compare the two datasets. It is certainly a disadvantage that a radar survey with adequate frequencies resolving the upper $100 \mathrm{~m}$ is not available along the flight profiles. We focus in this study on the question if the near-surface structure, which we assume to be represented by the TerraSAR-X scenes, is in coincidence with structures at greater depth, indicating that the near surface structure is a consequence of the formation of structures at greater depth. Variation of the back-scatter value potentially arise from inhomogeneities in the upper layers of firn, contributing to volume scatter or surface roughness that influences the scattering at the surface. These inhomogeneities might be hoar and ice layers, from drift snow forming wind crusts or summer surface melt that is more pronounced in depressions. Without firn core analysis a clear reason cannot be determined.

It has to be taken into account that the RES data were obtained in the presented region several years prior to the satellite data, so a displacement of several hundred metres between the two datasets occurs and thus a correlation coefficient of the location of the structure in RES and TerraSAR-X cannot be estimated. Therefore, we cannot contribute qualitatively to the discussion of Campbell et al. (2008), who have found no correlation between surface flow stripes of Kamb Ice Stream and signatures in radargrams crossing the ice stream.

The results of the classification are shown in Fig. 4a to 4d. The occurrence of internal layers (Fig. 4a) in the upper $30 \%$ of the profiles are displayed as light purple small dots, medium purple represents layering in the upper $60 \%$ of the ice column, while dark purple indicates layering that extends below that. Large dots beneath the small dots are marking a second block of internal layers at this location and the colour 


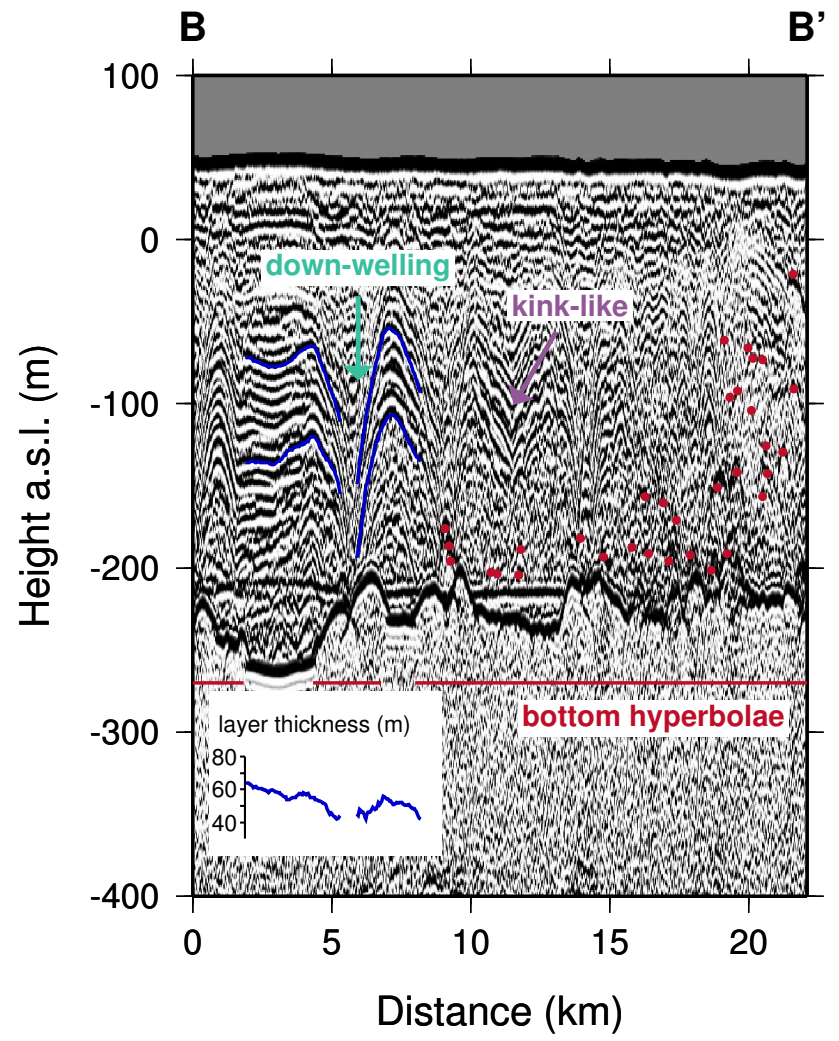

Fig. 3b. Radargram showing a $60 \mathrm{~ns}$ profile acquired 2001 ranging from $B$ to $B^{\prime}$ (locations of are shown in Fig. 2a). Sections with kink-like (purple) and down-welling (blue) layering are pointed out by arrows. Layer thinning coincident with down-welling is demonstrated by two arbitrarily chosen isochrones, highlighted by blue lines. The layer thickness between these isochrones is shown in the inset. Red dots and line are denoting internal and basal hyperbolae. The horizontal line at an elevation of approximately $-210 \mathrm{~m}$ is a multiple reflection between aircraft and surface.

represents the lower boundary of the layered package. Due to the low flow velocity of the ice shelf, internal layers in the upper part are formed by accumulation on the ice shelf during the flow northwards.

Hyperbolae were found at various depth: in Fig. $4 \mathrm{~b}$ the crests of those in the upper $30 \%$ of the ice column top are shown in light blue dots, between $30 \%$ and $60 \%$ in medium blue, from $60 \%$ to $90 \%$ in dark blue. The bold yellow line represent hyperbolae at the ice base, indicating sharp edges and crevasses. Basal hyperbolae are found almost everywhere in the ice stream and the western part of the ice shelf. In the latter an area close to the calving front appears to be free of hyperbolae. In this area we also found smooth horizontal layering. In the East, the shear margin and a boundary of about $50 \mathrm{~km}$ around the grounding line (also around the islands) exhibits basal hyperbolae.

Although the ice-water interface generally shows clear reflections (Fig. 4c), there are regions with missing (blue) and discontinuous (green) reflections. We propose that these kinds of reflections appear in areas where the base of the ice shelf is extremely rough. These types of reflections are located in the heavily rifted zone, close to the grounding line and at the margin of the ice stream.

Figure $4 \mathrm{~d}$ compiles the different shape of the layers wherever they are not horizontally oriented. At some locations we found ripple-shaped layers (displayed in orange), typically the pattern extends over $15 \mathrm{~m}$ in the vertical and appears rather regular. Down-welling and kink-like layers are solely found in the western rift zone, whereas rippled layering also appears in the ice stream. In the figures shown here we only display the appearance, or the horizontal location, of these classes, not the vertical distribution.

The distribution of surface and internal hyperbolae in combination with the internal layering, the resulting pattern matches well with the surface characteristics detected by TerraSAR-X. The low flow speeds in the western area of around $50-100 \mathrm{ma}^{-1}$ correspond (taking the different acquisition periods into account) to a shift of about 6-10 shots in the radargram, which is in the range of uncertainty for the classes that are concerned with variations of internal layers, or about 40 pixels in the TerraSAR-X mosaic.

The ice thickness data, taken from the same profiles used for the classification of the zones and even more profiles measured at lower vertical resolution, allow to inspect the large scale structure of the ice shelf. The thickness varies strongly across the ice shelf: between $90 \mathrm{~m}$ at the ice front in the East and $866 \mathrm{~m}$ an the inflow of the Jutulstraumen. Figure $2 \mathrm{~b}$ displays the obtained ice thickness in the western rift area in colour. The highly rifted area appears as a relatively thin area, with ice thicknesses less than $300 \mathrm{~m}$, whereas the ice west and south-west of it, as well as the extension of the ice stream contains ice 300 to $500 \mathrm{~m}$ thick. East of Novyy Island another thin, less than $300 \mathrm{~m}$ thick region exists. The ice just next to the inflow of Jutulstraumen is extremely thin, barely $200 \mathrm{~m}$ thick. At the calving front, the thickness of the ice stream decreases in its northern fifty kilometres from $300-350 \mathrm{~m}$ to about $90 \mathrm{~m}$ at the western tip of Trolltunga. Along the western ice front, this gradient equals to a change from approximately $220 \mathrm{~m}$ thick ice decreasing at the northern most $30 \mathrm{~km}$ to about $90 \mathrm{~m}$.

We will discuss the resulting zones (shown in Fig. 5) defined from surface characteristics and RES classification and their characteristics now in detail. Downstream the lee side of the rumple forms a long (about $55 \mathrm{~km}$ ), feature-free, narrow distinct zone (Zone 8). Eastwards of this lee side-zone a band of alternating short and non-sharp surface structures can be found (Zone 9). This band, which is also well visible in Fig. 2, is another distinct zone. On the westward side of the lee-zone, we find an area which exhibits a regular pattern, consisting of $15 \mathrm{~km}$ long stripes aligned perpendicular to the flow direction (Zone 6). The large scale structures visible are more pronounced in the radar image in Fig. 2 as the sensor penetrates into the ice, while optical imagery (not shown 


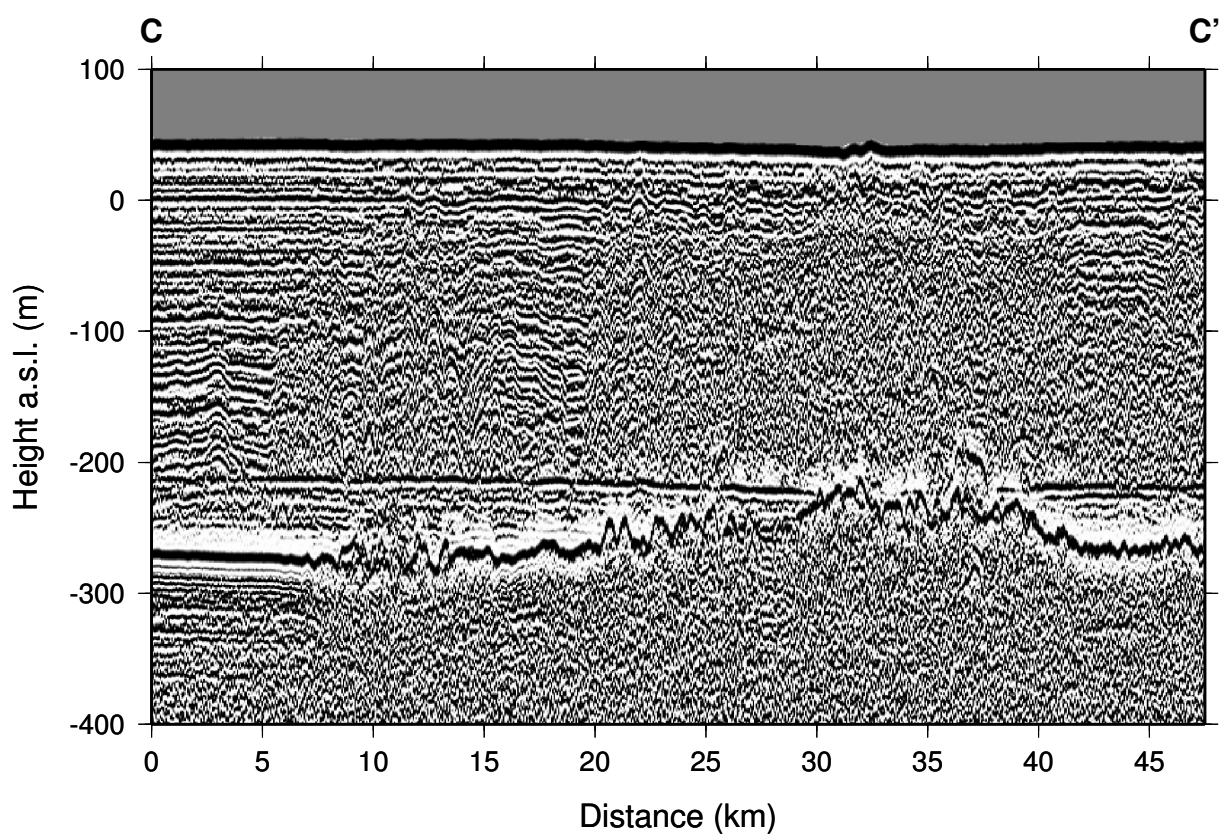

Fig. 3c. Radargram showing a $60 \mathrm{~ns}$ profile acquired in 2001 ranging from $C$ to $C^{\prime}$ (locations of are shown in Fig. 2a). The horizontal line at an elevation of approximately $-210 \mathrm{~m}$ is a multiple reflection between aircraft and surface.
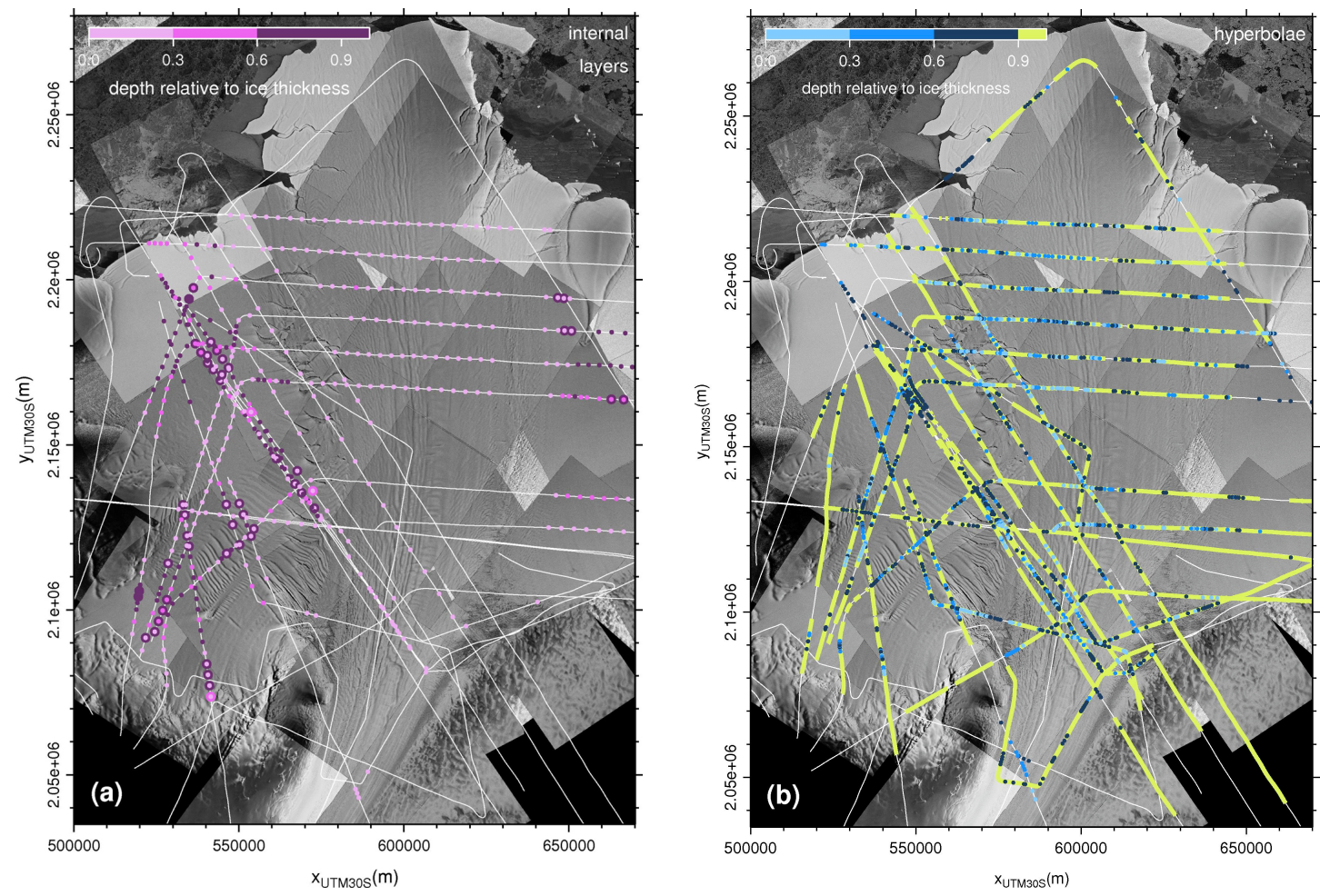

Fig. 4. First two of four maps displaying the RES classification of the internal structure superimposed on the TerraSAR-X mosaic. (a) Internal layers: light purple and medium purple denotes layers down to $30 \%$, respectively $60 \%$ of the ice thickness, dark purple full layering. Large dots beneath the small dots are marking a second block of internal layers. (b) Hyperbolae: light blue denotes hyperbolae located at the top, yellowish at the bottom, blue in the interior of the ice shelf and dark blue denotes hyperbolae at top and interior locations. 

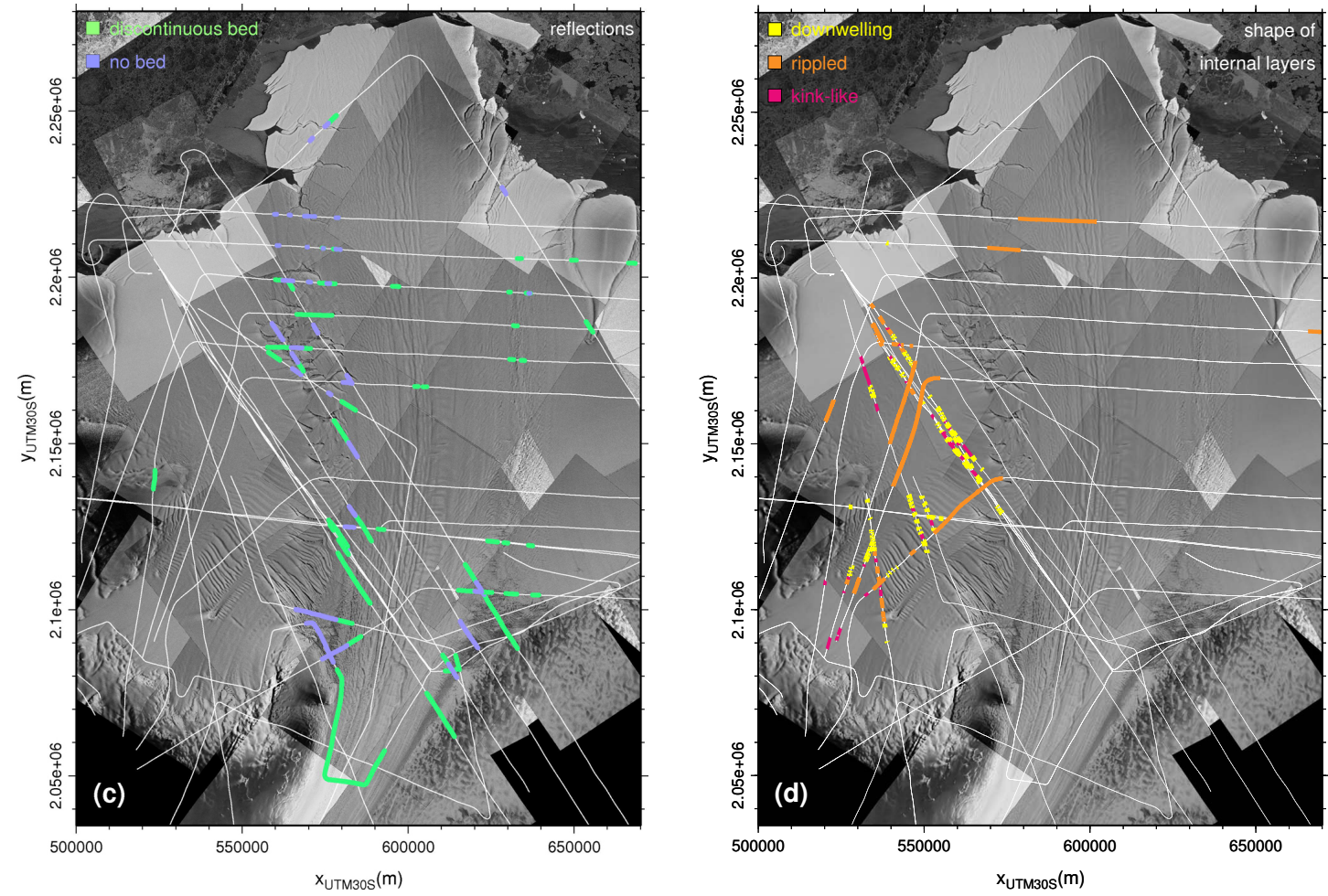

Fig. 4. Second two of four images displaying the RES classification of the internal structure superimposed on the TerraSAR-X mosaic. (c) Reflections: blue missing bottom reflection, green discontinuous reflections. (d) Shape of internal layers: down-welling in yellow, rippled shape in orange and kink-like in pink.

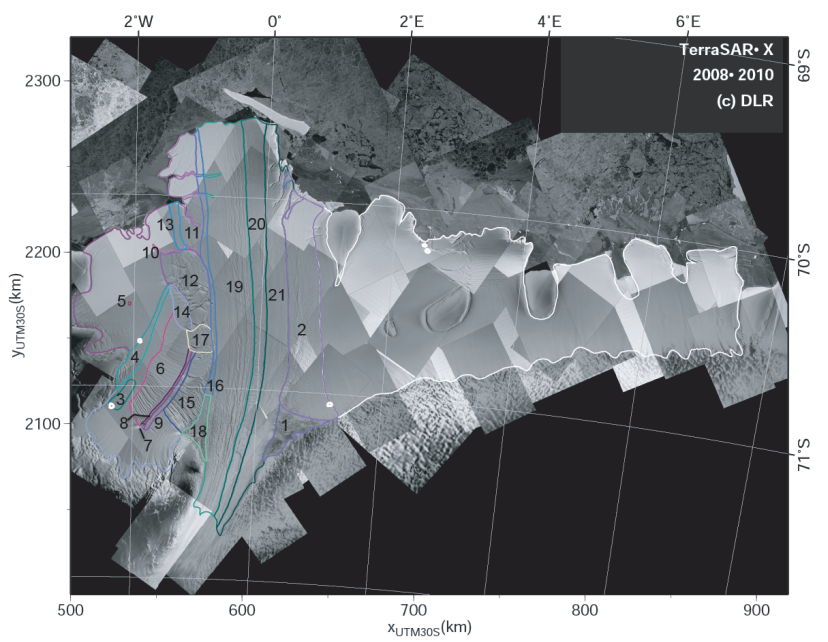

Fig. 5. TerraSAR-X mosaic and the sub domains defined from structural mapping of TerraSAR-X images and the RES classification.

here) rather suggests surface undulations then sharp-edged cracks.

The detailed structure of the grounded zone (Zone 7, Fig. 5) is shown in Fig. 6. Its size is about $3 \mathrm{~km} \times 3 \mathrm{~km}$.
The crevasse pattern and the absence of a dome-like surface elevation profile let us infer that this is an ice rumple. Ice rumples differ from ice rises by the fact that the ice flow is not divided around the obstacle, but the ice experiences a basal drag that leads to a rather minor distortion of the flow lines. As visible in Fig. 6a there is no division of the ice flow at the upstream end of the grounded area. This is a first indicator for an ice rumple. Figure $6 \mathrm{c}$ and $\mathrm{d}$ zoom into the grounded area and show its structure in a radar image (TerraSAR-X, c) and an optical image (ASTER, d). A comparison of these images reveals a field of fine scaled cracks across the grounded area, which undermines that the obstacle is overflown by ice. Thus, proving that this is an ice rumple. Nøst (2004) measured the water column thickness by means of seismics. This data shows, that south-west and north of the ice rumple the water depths is $>700 \mathrm{~m}$, indicating a rough seafloor topography.

In order to get more insight into the vertical structure and the mechanism that caused the structure, we inspect the radargram along two cross sections that are displayed in Fig. 3a and $3 b$ (for the locations of the profile see Fig. 2a) with a vertical exaggeration of 1:60. Figure 3a shows a radargram intersecting the large scale structures normal to the elongation (acquired 2004). The rumple is located about $8.5 \mathrm{~km}$ away from this profile and a line drawn perpendicular 

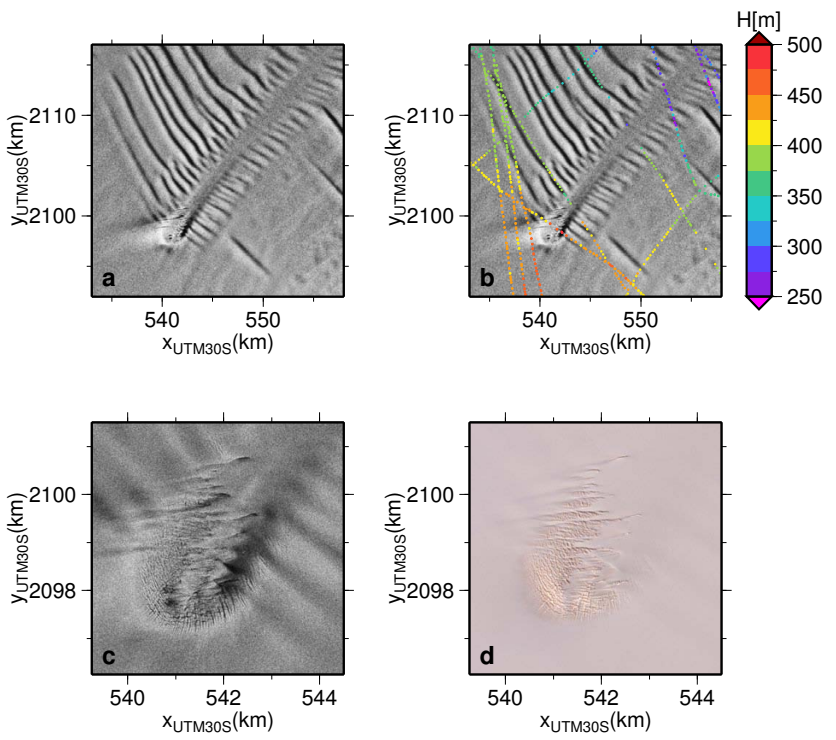

Fig. 6. Details of the ice rumple: (a) TerraSAR-X ScanSAR image taken on 5 November 2009. (b) same as (a) with superimposed RES ice thickness data. (c) TerraSAR-X stripmap mode image from 25 November 2008. (d) ASTER image of the same area as (c) from 6 August 2007.

to the flow direction would cross this profile at a distance of $0.7 \mathrm{~km}$. Hence, this profile shows the far field of the local influence of the ice rumple. The profile across the surface pattern reveals a very rough bottom topography. Blocks of undisturbed ice alternate with hyperbolae. Internal layers exist over the entire depth. They are elongated horizontally in the upper part, whereas the lower half shows irregular undulations of the layers. Closer to the ice rumple, the upper layers are affected as well and get a wiggly structure. Further downstream, now at the same level as the ice rumple, the layering at the lower part is destroyed and first few hyperbolae in the lower part appear. At this location, the TerraSAR-X image shows the first slightly darker shaded stripe. It takes however about $8 \mathrm{~km}$ until the layering in the upper part disappears and hyperbolae, as well as down-welling, appears. The RES profiles in the downstream area of the ice rumple exhibit several sequences of nearly undisturbed ice (Fig. 3a, $0.5 \mathrm{~km}$ to $1.5 \mathrm{~km}$ wide between distance $8.5 \mathrm{~km}$ to $48 \mathrm{~km}$ ) with full layering and no hyperbolae, intersected by steeply orientated surface layering, hyperbolae in the upper part and strongly pronounced at the base. Although the flight direction is almost perpendicular to the surface pattern and flow direction, the alternation is visible only in a very compact manner, the profile exhibits downwelling of the internal layers at distinct locations. Figure $3 b$ (taken in 2001) shows the downstream area of this pattern and the intersection in angle of about $45^{\circ}$ allows a rather zoomed view. The inset below the ice shelf base shows the thinning of a down-welling layer package between the two arbitrarily chosen isochrones, marked by dark blue lines, in the RES profile. Within the less than $3 \mathrm{~km}$ the thickness decreases from approximately $60 \mathrm{~m}$ to nearly $40 \mathrm{~m}$ before the layering gets too close for reliable layer tracing. The vertical displacement in the down-welled areas is in the order of $50 \mathrm{~m}$. The distance between the vertical layers is reaching the limit of the vertical resolution of the radar, which is $5-10 \mathrm{~m}$. The crest of the down-welling coincidences often with a bottom undulation and basal crevasses. The thickness change in these area amounts about 20-30 m. Locations which show the down-welling exhibit horizontal layers at the uppermost ten to fifty metres.

Switching back to the broader view, the zone that exhibits the down-welling in the vertical has been assigned to be another distinct zone. The margins of this zone have in a first guess been derived from the radar imagery, but improved by the RES data, as the western boundary was chosen such that the alternation between layering/no layering was absent. About $\sim 55 \mathrm{~km}$ downstream the ice rumple, east of the narrow band a field of fibre-like blocks of ice, which are partly bent, was identified (Zone 15). This area extends northwards to about the same latitude then the lee-zone and the narrow band.

Two further zones in the West were identified. Two are influenced by Novyy Island and two ice rises which are an extension of the Novyy Island. The southern zone is the lee side of a tiny ice rise close to Novyy Island (Zone 3). The second zone is most likely originated from outflow from Novyy Island into the ice shelf. Its margins can well be identified in the radar imagery (Zone 4).

The 1969 Belgian Antarctic Expedition (van Autenboer and Decleir, 1969) reported a potentially grounded spot with an ice thickness larger than the surrounding area. The navigation of that expedition faced unfortunately some major problems, so that the precise location is not known. However, they suggested the ice shelf to be grounded at $\sim 70.56^{\circ} \mathrm{S}$, $\sim 2.08^{\circ} \mathrm{W}$. Thus we defined Zone 5 around that spot, supported by a RES section close by, that is shown in Fig. 3c. The RES profile passes the spot in $500 \mathrm{~m}$ distance at kilometre 11. While north of the spot in the first $7 \mathrm{~km}$ of the profile full layering and a smooth bottom are detected, further south sequences of disturbed layering and bottom crevasses followed by inclined layering and less crevassed bottom are surveyed, similar, but less pronounced as in Fig. 3a.

The north-western part of the ice shelf, which appears rift free in the radar imagery (except very close to the calving front) high accumulation rates (Rotschky et al., 2007) and low flow speeds lead to the formation of internal layering. Zone 5 is located close to a RES section obtained in 2001, shown in Fig. 3c. Approximately at kilometre $\sim 11$ this profile passed in $500 \mathrm{~m}$ distance the suggested grounded spot. The RES profile shows lots of internal hyperbolae, presumably arising from basal crevasses. Although there is some ripple structure in the internal layers below the surface visible, the upper layers are unaffected and there is only a minor 
change in the ice thickness. Surface depressions that accumulate wind-blown snow and thus appear in the radar imagery as darker spots, are not formed. Consequently, this area does not leave a signature in the radar imagery. For the dynamics of the ice flow, this grounded spot means that the flow speeds are reduced to a certain amount. It is however interesting to note, that the spot is almost invisible in imagery, although the $50 \mathrm{~m}$ ice thickness change from the Belgian Expedition suggests a small dome-like structure visible. The RES data shown here, confirms the findings of van Autenboer and Decleir (1969), as the obtained thickness change is in our dataset $46 \mathrm{~m}$.

The most northwards zone in the West is a region that exhibits two stripes in flow direction, with a distance of few kilometres, elongated in flow direction (Zone 13). Westwards of this stripe the ice appears structure free. At the margins of this zone, the basal reflections where lost, indicating a very rough base. Nicholls et al. (2006) surveyed this area with an autonomous underwater vehicle and discovered too, that the ice has a very rough bottom topography.

South of this zone we find a single large rift that is $29 \mathrm{~km}$ long and has a maximum width of $\sim 1 \mathrm{~km}$. This rift is well visible also in ASTER images (not shown here), however, the radar imagery is advantageous here. The RES classification also reveals a change in properties across the rift (note that the RES data has been taken while the rift was further south). As this rift is separated from other structures, we assign this single feature an own zone (Zone 10).

Adjacent to the rift, a heavily crevassed, partly rifted area begins. We divided this area into three distinct zones, although there are no sharp boundaries between them. The structure of the entire area exhibits a clear boundary in the East towards the ice stream. The northernmost zone of the three (Zone 12) is characterised by wing-shaped rifts that are closely spaced, even interconnected on the western side. The southwestern side is less crevassed in the radar imagery. It exhibits rather extensions of the wing-shaped rifts and less dominant a similar pattern of undulations that we saw in the zone connected to the ice rumple. We assign this area a separate zone (Zone 14), as the damage visible on the surface is clearly less than in the real wing-shaped rift zone. The conjunction to the south is then the last of the three zones. The radar imagery shows again wing-shaped cracks, but with a lower density then northwards. This zone (Zone 17) is the direct extension of the zones generated by the ice rumple. The RES classification shows no internal layers in these areas and the zones have also a clear signature in the reflections: in some areas the bottom reflection is completely missing, in one profile discontinuous bottom reflections were found. Also hyperbolae in the interior are common.

The zones described above are located in the western rift area, which we aim to investigate. In order to understand the dynamics of this zone we need also to investigate the ice stream and as the dynamics of the ice stream is also influenced by its eastern margin, we go as far east as $1^{\circ} \mathrm{E}$ with the definition of zones. Beginning with the margin between the slow and fast moving ice masses in the west, we identified a zone which shows largely disturbed ice, fragments in form of blocks refrozen, which appears like a typical ice melange, directly north of Ahlmannryggen, where the Jutulstraumen leaves its lateral margins. This zone is narrowed down-stream and its surface characteristics changes as well, indicating that further north a zone of shear-margin type begins. The wedge shaped melange zone is defined as a single unit (Zone 18). It is has a counter part on the other side of the ice stream, which is discussed later in this section.

North of Zone 18, a region representing a typical shearmargin begins. This zone (Zone 16) is $\sim 3 \mathrm{~km}$ narrow and $\sim 155 \mathrm{~km}$ long. In the radar imagery this area extends up to the ice front at Trolltunga. It is interesting to mention, that this area is intersected by rifts from the western rift zone at one location in the middle part and twice from large rifts in the ice tongue far north. Except of two locations, the absence on continuous bed reflections is characteristic for Zone 16 and confirm the boundaries of this zone. At the northern end of Zone 16, we found an area that is confined in the South by the single large rift and in the West by Zone 13. The surface of this zone (Zone 11) exhibits an irregular pattern in the radar imagery. The RES data discloses gaps in the otherwise continuous basal reflections the north-south orientated rift which is also visible on the surface.

The fast moving area shows a complex pattern in the radar imagery, arising from the fast flow and the hinge zone at the grounding line. The radar imagery suggested zones along the entire length between grounding line and calving front. The RES classification of the hyperbolae reveals a difference between a western (Zone 19) and an eastern part, where basal hyperbolae are less frequent. In the TerraSAR-X mosaic, this part has a smoother surface and the structure of the surface is not aligned parallel to the flow as in Zone 19. The eastern part does, however, also not appear as one unit. Therefore we propose that there is a relative narrow band of similar structure (Zone 20), and a second wider band delimited by a shear margin (Zone 21). The middle part has less small scale cracks, but shows a pattern that is perpendicular to the flow, as if it would consist of single blocks. The definition of the zones in Jutulstraumen was also supported by flow modelling (which is otherwise not further discussed here), in which zones with a softening parameter were defined. In case the incorporation of an additional zone lead to more realistic flow fields, we kept the zone.

The transition between the fast ice stream and slow eastern part of the ice shelf is a rather wide zone $\sim 18 \mathrm{~km}$. It exhibits a dense field of tiny cracks in the TerraSAR-X mosaic (Zone 2). In the RES classification it appears as an area without internal layering, which is consistent from the characteristics of a shear margin. At the southern end of Zone 2, we find an area that is named Jutulgryta (Zone 1). Jutulgryta is known (Orheim et al., 1990a,b) to consist of an ice melange with icebergs, smaller fragments of meteoric ice, sea ice and 
intense melt ponds in summer. Therefore most profiles exhibit only discontinuous basal reflections. Furthermore, two potentially melange filled rifts at the eastern side of Trolltunga were identified in the TerraSAR-X mosaic.

\section{Discussion}

We hypothesize that the structure and dynamics of the western rift area, shown in Fig. 2, is dominated by two key areas: a small ice rumple at $71.2^{\circ} \mathrm{S} 1.85^{\circ} \mathrm{W}$ and Zone 15 , formed downstream of Trollkjelneset. The internal structure of the RES profiles found in the various sub regions reveals the flow history of the single segments of the ice shelf.

The influence of the ice rumple on the ice shelf is clearly visible in the the radar imagery as well as in the RES profiles crossing the region around the ice rumple and Zone 15. However, a first guess would be that the ice rumple is responsible for the entire rift formation in the West, whereas a detailed inspection shows that it affects only a limited area and does not cause the formation of the major rift system further north. The fish-bone pattern of surface stripes starting at the ice rumple, which is more pronounced in the west than in the East, is intersected by larger rifts only in the west, where these cracks form in Zone 15. The dark stripes never transform downstream into wide crevasses; the zone never loses its integrity. It should be mentioned, that the southernmost, youngest stripes are less pronounced, than the following, older ones, pointing out, that the processes enhancing the dark stripes act not locally at the ice rumple, but downstream. Far downstream the dark stripes widen and become less pronounced (less contrast between the stripes and the surrounding ice), as snow accumulation covers the structure formed by the ice rumple and the TerraSAR-X penetration depth allows to penetrate only a small fraction into the structure.

The along-flow structure gives rise to the question, which processes take place in the vicinity of the ice rumple and cause this structure. We consider three processes to take place: crevassing at the upper and/or lower surface, stretching and basal melting. They might appear in different combinations with each other, leading to four hypotheses for the evolution of the pattern:

i. The sticky spot and the steep change in water column thickness to the west (Nøst, 2004), leads to local basal melting, that causes thinning in form of channels and subsequently the layers sink. The thinned sections are subjected to tensile stress, that leads to stretching and thus narrowing of the layers. No crevasses are formed at all.

ii. Basal shear stress at the ice rumples leads to built up of tensile stress at the base which episodically becomes critical, forming basal crevasses. These are intersecting the lower layers. Melting enhances the thinning, which causes the down-welling of the layers. Tensile stress leads then to stretching.

iii. Sea level and ice thickness change induce a stick/slip motion, where during the stick mode stretching of the downstream area takes place and during slipping the layers remain undisturbed. The basal tensile stress remains sub-critical and thus the basal topography would exhibit undulations instead of basal crevasses.

iv. Cracks are formed at the surface and the base of the ice symmetrically, as indicated by fracture mechanics, leading to intersection of layers at the surface and base. Stretching thins the distance between the un-intersected layers and again, adjustment to hydrostatic equilibrium leads to sinking of the layers.

The former two hypotheses rely on basal melting, while the latter two are purely deformational and independent of the ability of the ocean for melting the bottom of the ice shelf. The dataset we are using gives no information at all if basal melting occurs. Nevertheless, hypothesis (i) describes a process that would not lead to a formation of new crevasses, whereas the RES sections show new hyperbolae, indicating cracks. Thus we see (i) as falsified. Hypothesis (ii) would require basal crevasses: the radar section show that upstream the rumple region, basal crevasses exist and the base of the ice shelf was never transferred to a smooth surface by melting. Nevertheless, the basal crevasses were obviously shallow, as the apex of the hyperbolae is at the lower boundary. Downstream the ice rumple new hyperbolae in the lower part, but up to about $30 \%$ of the thickness from the base, are created. This indicates deep crevasses or crevasses that deepened by melting, as the radargram does not allow to distinguish the two processes. An intersection of layers in the lower part is not clearly visible, however, small spots with layers remain in between the hyperbolae. However, it can neither be proven nor disproven.

Previous observations (Orheim et al., 1990a,b) and modelling (Khazendar and Jenkins, 2003; Holland et al., 2009) has suggested freezing to take place in suture zones and melange areas (Khazendar and Jenkins (2003) applies an ocean model to Zone 1), due to the gradients in the basal topography. According to the modelling studies freezing can either happen directly at the ice/ocean interface or frazil ice is formed in the water column and the crystals rise due to buoyancy and form a layer of marine ice. For both cases cold fresh water, typically melt water from nearby deep grounding lines, is required. The question that arises if this could take place in the basal crevasses that we observe. Both modelling studies are focusing on topographies that are different to the basal crevasses we found, as they deal with troughs rather than basal crevasses, narrowing towards higher elevations, having a sharp (hyperbola creating) crack tip. Khazendar and Jenkins (2003) found melting at the lower flanks of "rifts" (initial width $340 \mathrm{~m}$ ) in their two-dimensional steady 
state model and a layer of frazil ice that forms underneath the initial layer of sea ice. Holland et al. (2009) could model basal freezing at locations of steps in the basal topographies.

For testing the applicability of this freezing model to our site, we evaluated the validity of the hydrostatic equilibrium in Zone 6, 8 and 9, the entire downstream zone of the ice rumple. The basal signal is lost in the vicinity of the ice rumple, whereas $14 \mathrm{~km}$ further downstream the basal signal appears again. A plausible explanation for this is a rough ice base across the ice rumple and in its vicinity, leading to the loss of the basal signal. The downstream retrieval of a basal signal requires a smoothing of the ice base and we suggest that this is due to melting. The surface elevation over and in the vicinity of the ice rumple in Zone 8 is lower than that of the surrounding ice in the West (Zone 6) and East (Zone 9). Downstream the ice in Zone 6 and 9 thins and the surface over these three zones levels more and more out. However, the base of Zone 8 remains downstream higher elevated compared to Zone 6 and 9. This basal trough is at most in the order of $10-20 \mathrm{~m}$. In case this trough is filled with marine ice, the surface should be at the same level as the one east and west of the trough. An accuracy of the surface elevation $<0.5 \mathrm{~m}$ is required to clarify if the hydrostatic equilibrium requires the accretion of marine ice. Our accuracy is unfortunately not sufficient. Consequently, we have to conclude that we do not find any evidence for marine ice, but a $10-20 \mathrm{~m}$ thick marine ice layer in the northern part of Zone 8 would be consistent with the observations we made.

However, we propose that another type of freezing will take place immediately when the crack propagates, which is a process taking place on the time scale of seconds. The crack propagates into cold ice, which might be in case of Fimbulisen more than $10^{\circ} \mathrm{C}$ below the freezing temperature of sea water (Humbert, 2010). We suggest that freezing will immediately happen when the crack surfaces form and cover the meteoric ice with a shallow marine ice layer. We suggest that this even reduces the load at the crack tip and prohibits the crack to become unstable.

The basal undulations suggested by hypothesis (iii) can be disproven by the RES sections. A hyperbola is supposed to be formed where a sharp crack exists, whereas moderate basal undulation cannot produce a basal hyperbola. There are clearly cracks and crevasses at the lower surface. However, the distance between the location of down-welling and near surface hyperbolae, changes with along the profile perpendicular to the ice flow (Fig. 3a) and the distance between the dark stripes in Figs. 2 and 6 is not constant, although the pattern is partly regular. This makes a change in the basal regime at the ice rumple on the timescale of decades likely.

Hypothesis (iv) proposes surface crevasses, thus we try to test this hypothesis by investigating the location of hyperbolae and surface cracks visible in the TerraSAR-X images. The RES sections reveal $10-15 \mathrm{~km}$ downstream the location of the rumple first hyperbolae with an apex at about $30 \%$ of the ice thickness below the surface. At the same locations, hyperbolae at about $1 / 2$ to $2 / 3$ of the depth exist, as well as hyperbolae of about $15 \%$ above the lower surface. Coincidentally, the near surface layers are down-welled. Below the apex of the uppermost hyperbolae no layering exists. The absence of near surface hyperbolae further upstream let us suggest that hyperbolae are formed close to the location we observe them and thus about $10-15 \mathrm{~km}$ downstream the ice rumple. They are thus a secondary step of the impact of the basal shear stress over the rumple. However, hypothesis (iv) requires the coincidence of surface and basal crevasses. The hyperbolae are clearly not located at the surface, nor is there any hint in TerraSAR-X images that surface crevasses in coincidence with the dark stripes exist (whereas few narrow, short cracks on the sides of the dark strips exist, possibly arising from bending stresses). The crests of the hyperbolae are so far below the surface, that we cannot claim them to be surface crevasses. They seem to be formed below the ice surface, potentially the hyperbolae are originated by a basal crevasse that starts at the lee zone of the rumple, propagating westwards as well as upwards. This is also undermined by the fact that the crests of the hyperbolae further upstream on the RES section are located deeper, thus the cross section shows a slice of the flow history, in which the propagation reached different vertical levels. It remains however unclear why the cracks have not propagated through the ice shelf entirely, but were arrested just about $120 \mathrm{~m}$ below the surface.

These stripes of down-welling remain in Zone 6 in the flow history for the subsequent $85 \mathrm{~km}$ in an area which is dominated by tensile stress, before they experience shear at the northernmost part of Zone 6 where this zone merges with Zone 17. The tension stretches the ice at the locations where the ice was intersected by the basal crevasses more than the undisturbed units and widens these zones. This is visible in the radar imagery in Fig. 2, as well as in the RES section in Fig. 3a. The signature in the radar section in Fig. 3b becomes more complex, as the flight direction is no longer parallel to the flow direction. Kinks in the internal layers appear as in Fig. $3 \mathrm{~b}$ at distance $1.5 \mathrm{~km}$, wherever the RES sections cross a dark stripe in the TerraSAR-X scenes in directions other than perpendicular to the flow direction. The kinks and down-welled zones, which appear much wider in the non-perpendicular sections thus represent a zoom into the structure of the dark stripes. These sections also allow us to conclude that the pattern all over the dark stripes in Zone 6 are in general similar.

In conclusion a new hypothesis with the verified components from the above listed hypothesis can be formulated: when the ice passes the ice rumple, basal crevasses are formed, which penetrate laterally eastwards and westwards. They extend in the profile only in the lower third of the ice column. Downstream the cracks propagate vertically, either due to load at the crack tip arising from the water pressure, or tensile stress that overcomes the cryostatic contribution in size still arising from the basal shear stress. The locations 


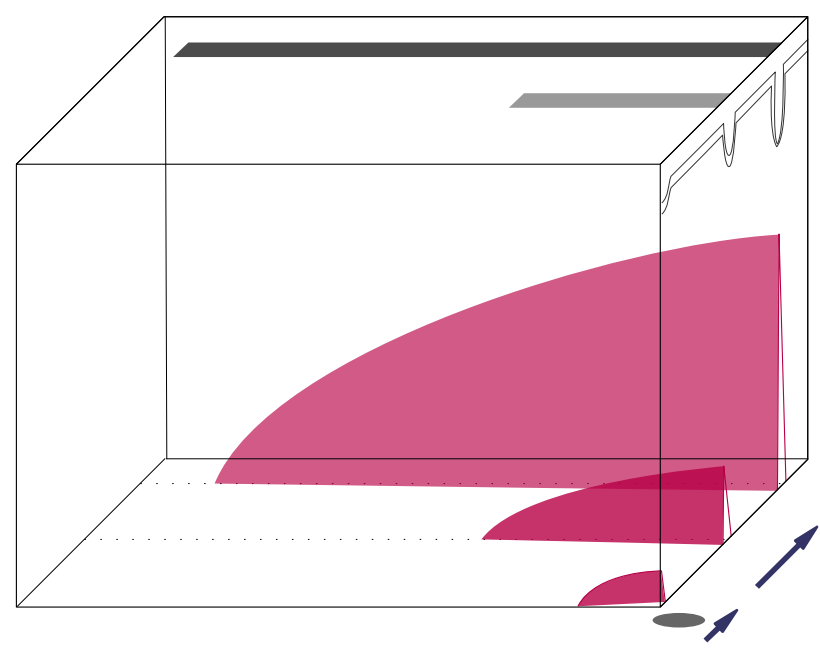

Fig. 7. Sketch illustrating the origin of the surface and internal structure north-west of the ice rumple shown Fig. 6.

of the cracks represent sections of thinner ice, potentially enhanced by basal melting, and thus the horizontal layers are welled down. Additionally the trough in the surface elevation leads to intensified snow accumulation by wind-blown snow. This causes the darker zones in the TerraSAR-X images. Further downstream the ice experiences tension, leading to stretching of the thinner sections, that results in narrowing of the distance of the internal layers and widening of the sections. Figure 7 displays this in form of a cartoon, showing the basal crevasses, the surface structure and the down-welling at the side of the block.

In order to complete the discussion of the effect of the ice rumple we are now considered with the zone east of the lee zone, Zone 9. What applies for Zone 6 also holds for Zone 9, nevertheless its lateral extent is obvious much less. We suggest that this is due to an inhomogeneous flow unit, that originates at the grounding line. This flow unit arrests the crack propagation. Hulbe et al. (2010) found similar crack arrest in the Ronne Ice Shelf. In the flow history both zones, Zone 6 and 9 , never loose their integrity, the basal crevasses never penetrate up to the surface. At few locations crevasses from other areas propagate into these areas.

The loss of the lateral margin at Ahlmannryggen in Zone 15 rises the tensile stress and leads to crack formation at the eastern margin of this zone. The cracks propagate laterally and generate individual blocks of undisturbed ice that are connected to each other only to a minor extent. They experience at the area of the formation of the blocks only tensile stress, which is evident as the ice is not bent in any direction. Further downstream the merging of the ice masses build up compressive stress. The compressive stress leads to a separation of the crevassed western ice mass into individual fibres. The fibres become bent and even folded. The built up of shear stress increases the separation of the fibres, thus a propagation from crevasses to rifts, and thus to distortion of some plains. From there on, the structure of the western rift area is formed by the shear stress between the slower moving western part and the fast ice in the centre. In contrast to wing cracks, that are formed when rifts are experiencing compressive stress, the orientation of the bent ends of the rifts here is opposite and thus points out that the rifts are deformed under shear stress. The northernmost, large rift (Zone 10) exemplifies this situation best.

Severe shearing between the fast flowing region of the Jutulstraumen and the heavily crevassed neighbouring regions on its western side causes the loss of basal reflections. Although Zone 16 appears in the radar imagery as a narrow band that reminds on a shear zone, it is not decoupling the flow in the central from the west. The same applies to Zone 18, which nourishes Zone 16. Both zones are strong enough to sustain the shear and transmit it to the western part of the ice shelf. We claim that the lateral stretching of Jutulstraumen after it passed the narrow valley, visible as a widening of the cross section of the ice stream in the radar imagery, is the reason for this coupling. In the broader perspective, the reason for the western rift system is the fact that no typical shear margin is formed along the western margin of the ice stream. With a real shear margin that decouples the two parts of the ice shelf, such an area full of large rifts and crevasses could not have been evolved.

The combination of the two radar datasets gave insight into many structures found in Fimbulisen. This raises the question if radar imagery can solely serve as a diagnosis tool for internal structures and deliver suggestions for radio echo sounding surveys. As we have seen for Zone 5 a structurefree surface in the TerraSAR-X does not allow to assume, that the internal structure does not consist of down-welling, kink-like or rippled layers. The opposite is nevertheless true: wherever the surface exhibits a structure, the internal structure and often the base is not smooth.

\section{Conclusions}

In total twenty-three $150 \mathrm{MHz}$ RES profiles surveyed with a 60 ns pulse and one with 600 ns obtained between 19962008 we found down-welling of internal layers, as well as rippled and kink-like internal layers, partly with kinks and steep gradients. The channelised flow of Jutulstraumen into the ice shelf destroyed the internal layering in the ice stream, so that deep layering appears only in the slow flowing areas in the of the ice shelf. The majority of the hyperbolae were located at the base or in the lower third of the ice shelf, indicating generally a rough bed. In the vicinity of large rifts and at the margin of the ice stream the basal reflections were lost.

A mosaic of TerraSAR-X radar scenes, acquired between 2008 and 2010 in stripmap and ScanSAR mode, covering the entire ice shelf, serves as a base for the detection of units with identical properties. Because the X-band radar signal 
penetrates into the upper 8-10 $\mathrm{m}$ of the ice, these images allow a much more detailed identification of spatial units, even though crevasses and flow stripes might be covered by fresh snow, than purely optical sensors.

The morphological interpretation of the combination of RES and X-band radar imagery data lead to the identification of 26 structurally distinct domains. RES sections reveal that the surface characteristics detected in the TerraSAR-X data are a consequence of the vertical structure and therefore always represent inhomogeneous ice.

The structure and dynamics of the western rift area, shown in Fig. 2, is caused by (i) a small $\left(3 \times 3 \mathrm{~km}^{2}\right)$ ice rumple at $71.2^{\circ} \mathrm{S}, 1.85^{\circ} \mathrm{W}$ and (ii) a zone with fibre-like ice blocks that is formed at the junction between Jutulstraumen and the slower, thinner western part ice shelf:

i. The rumple changes the structure of the ice shelf through the entire thickness (see Fig. 3a and 3b) in its vicinity and $25 \mathrm{~km}$, downstream over width of about $10 \mathrm{~km}$. Although the vertical structure exhibits strong deformation of the internal layers and also hyperbolae throughout the thickness, it never loses entirely its integrity and does not contribute to the formation of rifts.

ii. The inflow in the western part of the ice shelf loses its lateral constraint at Ahlmannryggen, where crevasses were formed. The contact of the eastern end of this flow unit with Jutulstraumen exerts compressive stress that leads to separation into blocks, which are later on bent and folded like fibres. We infer that this process is the origin of the western rift zone. Northwards, the rifts are prone to shear, leading to wing formation and growth.

Although we found a narrow band between the ice stream and the western rift zone, this band does not prohibit the transmission of shear on the ice masses in the west. The western rift zone is thus also a consequence of a strong mechanical coupling, or an absence of decoupling, of the two merging parts of the ice shelf.

Acknowledgements. This study was supported by the German Research Foundation (DFG) under grants HU 1570/2-1 and the cluster of excellence CliSAP at the KlimaCampus of the University of Hamburg. The TerraSAR-X images were provided by the German Aerospace Center (DLR) under proposal LAN0013. We thank Robert Metzig (DLR) for the support in acquiring the TerraSAR-X images. ASTER images were provided by the European Space Agency under IPY AOPOL.4032. The radio echo sounding data was partly acquired in the VISA-Project (DFG Research Grant Jo191/8-1\&2). A. H. want to thank Roland Warner (ACE and CRC, Hobart, Australia), Dietmar Gross (TU Darmstadt), Robert Metzig (DLR) and Dana Flouricou (DLR) for fruitful discussions. We thank Johannes Lohse for support of the classification of the RES data. Many thanks to Daniela Jansen and an anonymous reviewer for their detailed and thoughtful reviews.

Edited by: G. H. Gudmundsson

\section{References}

Blindow, N.: The central part of the Filchner-Ronne Ice Shelf, Antarctica: internal structures revealed by $40 \mathrm{MHz}$ monopulse RES, Ann. Glaciol., 20, 365-371, 1994.

Campbell, I., Jacobel, R., Welch, B., and Pettersson, R.: The evolution of surface flow stripes and stratigraphic folds within Kamb Ice Stream: why don't they match, J. Glaciol., 54, 186, 421-427, 2008.

Davis, C. H. and Poznyak, V. I.: The depth of penetration in Antarctic firn at $10 \mathrm{GHz}$, Geosci. Rem. Sens., 31, 1107-1111, 1993.

Fritz, T. and Eineder, M.: TerraSAR-X Ground Segment Basic Product Specification Document, Tech. rep., DLR, 2009.

Holland, P. R., Corr, H. F. J., Vaughan, D.G., Jenkins, A., and Skvarca, P.: Marine ice in Larsen Ice Shelf, Geophys. Res. Lett., 36, L11604, doi:10.1029/2009GL038162, 2009.

Hulbe, C. L., LeDoux, C., and Cruikshank, K.: Propagation of long fractures in the Ronne Ice Shelf, Antarctica, investigated using a numerical model of fracture propagation, J. Glaciol., 56, 197, 459-472, 2010.

Humbert, A.: The thermal regime of the Fimbul Ice Shelf, Antarctica, Ann. Glaciol., 51, 56-64, 2010.

Khazendar, A. and Jenkins, A.: A model of marine ice formation within Antarctic ice shelf rifts, J. Geophys. Res., 108, C7, 3235, doi:10.1029/2002JC001673, 2003.

McClain, E. P.: Eleven year chronicle of one of the world's most gigantic icebergs, Mariners Weather Log, 22, 328-333, 1978.

Nicholls, K. W., Abrahamsen, E. P., Buck, J. J. H., Dodd, P. A., Goldblatt, C., Griffiths, G., Heywood, K. J., Hughes, N. E., Kaletzky, A., Lane-Serff, G. F., McPhail, S. D., Millard, N. W., Oliver, K. I. C., Perrett, J., Price, M. R., Pudsey, C. J., Saw, K., Stansfield, K., Stott, M. J., Wadhams, P., Webb, A. T., and Wilkinson, J. P.: Measurements beneath an Antarctic ice shelf using an autonomous underwater vehicle, Geophys. Res. Lett., 33, L08612, doi:10.1029/2006GL025998, 2006.

Nixdorf, U., Steinhage, D., Meyer, U., Hempel, L., Jenett, M., Wachs, P., and Miller, H.: The newly developed airborne RESsystem of the AWI as a glaciological tool, Ann. Glaciol., 29, 231-238, 1999.

Nøst, O. A.: Measurements of ice thickness and seabed topography under the Fimbul Ice Shelf, Dronning Maud Land, J. Geophys. Res., 109, C10010, doi:10.1029/2004JC002277, 2004.

Orheim, O., Hagen, J. O., and Østerhus, S.: Studies on, and underneath, the ice shelf Fimbulisen, Norsk Polarinstitutt. Meddelser, 113, 59-73, 1990a.

Orheim, O., Hagen, J. O., Østerhus, S., and Sætrang, A. C.: Glaciologic and oceanographic studies on Fimbulisen during NARE 1989/90, FRISP Rep., 4, 120-131, 1990 b.

Rotschky, G., Holmlund, P., Isaksson, E., Mulvaney, R., Oerter, H., Van den Broecke, M. R., and Winther, J.-G.: A new surface accumulation map of western Dronning Maud Land, Antarctica, from interpolation of point measurements, J. Glaciol., 53, 182, 385-398, 2007. 
Rott, H., Sturm, K., and Miller, H.: Active and passive microwave signatures of Antarctic firn by means of field measurements and satellite data, Ann. Glaciol., 17, 337-343, 1993.

Swithinbank, C. W. M., McClain, P., and Little, P.: Drift Tracks of Antarctic Icebergs, Polar Rec., 18, 495-501, 1977.

Ulaby, F. T., Moore, R. J., and Fung, A. K.: Microwave Remote Sensing, Active and Passive, vol. II, Artech House Inc., 1982. van Autenboer, T. and Decleir, H.: Airborne radio-glaciological investigations during the 1969 Belgian Antarctic Expedition, Bulletin de Société belge de Géologie, de Paléontologie et d'Hydrologie, 78, 2, 87-100, 1969.

Vinje, T. E.: Frift av Trolltunga i Weddellhavet, Norsk Polarinstitutt. Arbok, 213 pp., 1975. 